\title{
Immediate recall as a function of grammatical structure and mode of presentation
}

JOSEPH A. BRYK AND DANIEL C. O'CONNELL

SAINT LOUIS UNIVERSITY

Immediate written recall of nonsense strings was studied in a 3 by 2 factorial design: structure (none, morphology, morphology and syntax) and mode of presentation (vertical and horizontal). Each $S$ recalled a string to criterion of two errorless trials in at least 10 trials. Measures of recall indicated facilitation by structure in both modes of presentation. Multiple comparisons revealed no differences between the two levels of structure. Serial position of first written response differentiated modes of presentation in the nonstructured condition.

Epstein $(1961,1962,1963)$ found that the presence of function words (e.g., a, the) and bound morphemes

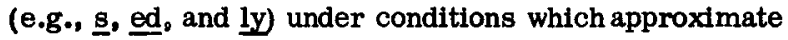
the structure of English syntax significantly increases the immediate recall of nonsense strings when compared to control strings which do not approximate English syntax. The effect appeared to be invariant under conditions in which the strings are presented in their entirety; however, serial presentation eliminated the effect. In an attempt to further explicate the potency of the effect, Forster (1966) studied the influence of syntax using a nonordered (free) recall task; his results confirmed facilitation due to syntax, and, further, the presence of bound morphemes without syntactic structure was found to have no effect on nonordered recall when compared to strings which did not possess such bound morphemes.

Bogartz \& Arlinsky (1966) failed to find facilitation due to syntax when immediate (ordered) recall of strings possessing both function words and bound morphemes in syntactic order was compared to recall of strings possessing either function words or bound morphemes alone. The separate faclititive effects of function words and bound morphemes were found to be significant, however, when compared to appropriate control strings which lacked elther of them. The interpretation of Bogartz and Arlinsky's findings is inconclusive, however, because they failed to include a condition in which both function words and bound morphemes were present but in nonsyntactic order. Utilizing orally presented strings in which such a comparison string was present, O'Connell, Turner, \& Onuska (1967) found that syntax did not facilitate ordered recall under conditions of either intonated or monotone presentation. Further negative evidence regarding the facilitative effects of syntax was reported by Rosenberg (1964), who found that the addition of bound morphemes in syntactic order to short ( 5 unit) strings did not facilitate their immediate recall.

These failures to find facilitative effects for syntactic structure suggest the need for further empirical study. The present experiment sought to assess the immediate recall of strings which possessed both function words and bound morphemes but which varied with regard to the presence of syntax. As an added control, a string which was identical in regard to unit size at each position within the string but which lacked both function words and bound morphemes was generated. Furthermore, in order to specify the influence which mode of presentation has upon the immediate recall of such strings, vertical $(V)$ and horizontal $(H)$ modes of presentation were factorially varied within the experiment. Previous findings (Bogartz \& Arlinsky, 1966) suggested that such a perceptual variation did not influence the perception of the string in its entirety. Since the hypothesis that horizontal presentation of the strings would preserve the perceptual unity more than vertical presentation seemed reasonable, it was hoped to substantiate this finding with the present materials.

Stimuli

Three modified strings of 10 nonsense words were adopted from Epstein's (1961) original strings. The modifications were introduced in order to equate strings for number of letters (40) as well as for number of letters in each word at each position. The high structure (HS) string included both morphology and syntax: The haky deebs reciled $u$ dison a flutest pava kex. The string with low structure (LS) simulated English morphology but without syntax: kex haky dison flutest a deebs $u$ reciled pava the. Finally, the string with no structure (NS) lacked both morphology and syntax: tah pava sdeeb festlut $u$ dison e leirdec hyka kex. In addition, the high structure string began with a capital letter and ended with a period; all other letters were typewritten in lower case.

Each string was presented on a sheet of 8-1/2 $x$ 11 in, paper. Within individual words, typing was from left to right, but the string of words was typed either horizontally or vertically.

Subjects

The Ss were 30 undergraduate women from Maryville College. The volunteers were randomly assigned to experimental groups in a 3 by 2 (structure by mode of presentation) factorial design and run individually by the first author.

\section{Procedure}

All Ss received identical instructions to learn the string in its entirety and in the correct order. Each $S$ was shown the string for 20 sec. On each trial, a free written recall period of $30 \mathrm{sec}$ followed. Each $\mathrm{S}$ was also shown beforehand a sample string which consisted of six nonsense syllables from the 50\% range of meaningfulness in Archer's (1960) norms. This string was typed horizontally or vertically, depending on which experimental group $S$ was assigned to. The Ss wrote their responses on $5 \times 8$ in. sheets of 
paper marked off with 10 lines, each $1.5 \mathrm{~cm}$ in length. The lines were arranged either horizontally or vertically on the page to correspond to the mode of presentation used for each $\mathrm{S}$. Each $\mathrm{S}$ received a minimum of 10 trials and continued until a criterion of two perfect recalls in succession had been reached. Throughout the experiment E remained seated behind $S$ and recorded the serial position at which she began each written recall trial. Results

Mean response measures are given in Table 1. For each response measure, an analysis of variance with a 3 by 2 (structure by mode of presentation) factorial design revealed a significant main effect for structure: for trials to one errorless trial $(F=6.20, d f=2 / 24$, $\mathrm{p}<.01)$; for trials to two errorless trials $(\mathrm{F}=9.16$, $\mathrm{df}=2 / 24, \mathrm{p}<.005)$; for items correct in the first 10 trials ( $F=7.22$, df $=2 / 24, p<.005$ ); for letters correct in the first 10 trials $(F=12.72, d f=2 / 24, p<.005)$; for correct items to the more difficult criterion ( $F=$ 5.98, $\mathrm{df}=2 / 24, \mathrm{p}<.01$ ); and for serial position of the first response of each trial $(F=4.75$, df $=2 / 24, p<.01)$. With one exception, mode of presentation and interaction effects were nonsignificant. The exception involved the measure of serial position of first written responses; mode of presentation $(F=3.32, \mathrm{df}=1 / 24$, $\mathrm{p}<.05)$ and the structure by mode interaction $(F=3.42$, $\mathrm{df}=2 / 24, p<.01$ ) were both significant. The effect is illustrated in Fig. 1.

For each response measure, the significant effect of structure was submitted to Scheffe's test in order to localize the effect more specifically. In every instance, morphology and syntax together yielded a significant difference from the condition with no structure at all. With the one exception of serial position of first written responses, morphology alone (low structure) yielded a significant difference from the condition with no structure at all. In all instances, the differences between the two levels (low and high) of structure were nonsignificant.

\section{Discussion}

Confirmation of the general effect of facilitation of immediate recall by structure is clearly indicated in the present research. The more specific locus of the effect, however, remains in question. The present results indicate that morphology is the significant factor; in no instance is the presence of syntax significantly facilitative over and above the influence of morphology alone. For-

Table 1. Mean Response Measures

\begin{tabular}{|c|c|c|c|c|c|c|}
\hline Condition & $\begin{array}{l}\text { Trials } \\
\text { to lst } \\
\text { Correct } \\
\text { Trial }\end{array}$ & $\begin{array}{l}\text { Trials } \\
\text { to } 2 \\
\text { Correct } \\
\text { Trials }\end{array}$ & $\begin{array}{l}\text { Items } \\
\text { Correct } \\
\text { in lst } 10 \\
\text { Trials }\end{array}$ & $\begin{array}{l}\text { Letters } \\
\text { Correet } \\
\text { in lst } 10 \\
\text { Trials }\end{array}$ & $\begin{array}{l}\text { Items } \\
\text { Correct } \\
\text { to More } \\
\text { Difficult } \\
\text { Criterion }\end{array}$ & $\begin{array}{l}\text { Serial } \\
\text { Position } \\
\text { of Ist } \\
\text { Written } \\
\text { Response }\end{array}$ \\
\hline H - NS & 6.4 & 8.2 & 78.2 & 334.0 & 7.5 & 1.5 \\
\hline$H=L S$ & 3.2 & 5.2 & 88.4 & 370.2 & 8.6 & 2.2 \\
\hline$H-H S$ & 3.2 & 4.2 & 93.6 & 382.6 & 8.6 & 1.0 \\
\hline$V$ - NS & 6.4 & 8.2 & 81.2 & 334.2 & 7.9 & 3.8 \\
\hline$V=L S$ & 4.2 & 4.6 & 91.4 & 365.8 & 8.6 & 2.0 \\
\hline$V=H S$ & 3.4 & 4.4 & 92.6 & 377.6 & 8.6 & 1.1 \\
\hline
\end{tabular}

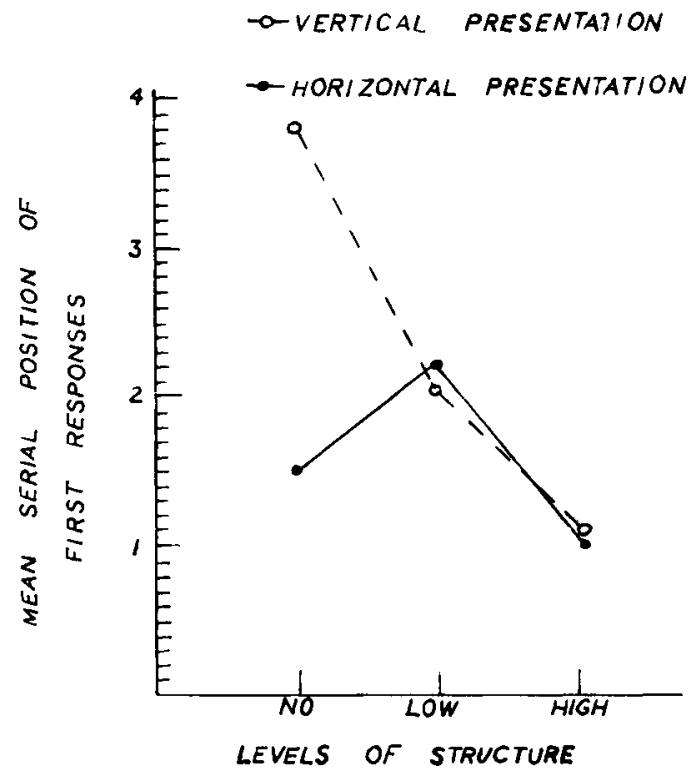

Fig. 1. Mean serial position of first responses.

ster's (1966) results indicated quite the opposite, that is, facilitation due to syntax, but not to morphology. Our results are in accord with the findings of $O^{\prime}$ Connel, Turner, \& Onuska (1967), who found the same effect with both intonated and monotone presentation of variously structured strings.

The one significant result due to structure which must be ascribed to the presence of syntax rather than to the morphological factor is the shift in the serial position of the first written response. Here too, the influence of presentation shows its only significant influence. It is evident from Fig. 1 that horizontal and vertical presentation affect the serial position of the first written response quite differently in the unstructured condition; vertical presentation displaces considerably the ordinarily preferred initial serial position. With the addition of structure, the tendency of Ss is to start, responding with the beginning of the string, as in ordinary language behavior.

References

Archer, E. J. A re-evaluation of the meaningfulness of all possible CVC trigrams. Psychol. Monogr., 1960, 74, No. 10 (Whole No. 497).

Bogartz, W., \& Arlinsky, M. Effects of two components of syntax on rote verbal learning. Psychon. Sci., 1966, 6, 517-518.

Epstein, W. The influence of syntactical structure on learning. Amer. J. Psychol., 1961, 74, 80-85.

Epstein, W. A further study of the influence of syntactical structure on learning. Amer. J. Psychol., 1962, 75, 121-126.

Epstein, W. Temporal schemata in syntactically structured material. J. gen. Psychol., 1963, 68, 157-164.

Forster, K. I. The effect of syntactic structure on nonordered recall. J. verbal Learn. verbal Behav., 1966, 5, 292-297.

O'Connell, D. C., Tumer, E. A., \& Onuska, L. A. Intonation, grammatical structure, and contextual association in immediate recall. J. verbal Learn. verbal Behav., 1967, in press.

Rosenberg, S. Recall of nonsense sentences as a function of grammatical cues. Paper presented to the Psychonomic Society, Niagara Falls, Canada, 1964.

Note

1. The research reported here has been supported in part by a Ford Foundation Faculty Grant to the second author. 